\title{
LAS COFFEE HOUSES INGLESAS: UN NUEVO ESPACIO PARA LA INTERACCIÓN SOCIAL EN EL SIGLO XVII
}

\author{
English Coffee Houses: A New Space \\ for Social Interaction in the $17^{\text {th }}$ Century \\ Manuel ACÓN PÉREZ 1 \\ Universidad de Zaragoza
}

\section{Resumen}

Durante la segunda mitad del siglo XVII las coffee houses proliferaron en Inglaterra y, lejos de ser un fenómeno excepcional, estaban totalmente integradas en la vida cotidiana del país. Eran establecimientos públicos a los que podía acceder cualquier hombre, siempre que tuviera dinero para permitirse una taza de café. Se convirtieron en lugares de interacción social alejados de la esfera privada -el hogar- y de la esfera de autoridad - la corte-, que alcanzaron reconocimiento gracias a sus ideales de sociabilidad, debate e igualitarismo. Las coffee houses se convirtieron en el reflejo de la vida cotidiana de una nueva clase media emergente, en la que el empirismo y el refinamiento comenzaban a aflorar. Quedaron vinculadas al incipiente mercantilismo de la época, pero igualmente tuvieron especial incidencia en la política y la cultura inglesas. También recibieron críticas, especialmente desde el ámbito femenino, aunque debemos considerarlas como una oposición frente a la exclusión que las mujeres sufrían para poder acceder a determinados ámbitos públicos. En definitiva, la aparición de las coffee houses supuso la creación de un nuevo espacio de sociabilidad donde no se trata de excluir a ningún sector social y donde las opiniones comenzaron a convertirse en opinión pública.

Palabras clave: coffee house, sociabilidad, espacio público, siglo XVII, Inglaterra

1 Licenciado en Derecho, graduado en Historia y posgraduado en el Máster Universitario en Investigación y Estudios Avanzados en Historia de la Universidad de Zaragoza. Correo electrónico: 141293@unizar.es Fecha de recepción del artículo: 31 de octubre de 2017. Fecha de aceptación: 15 de enero de 2018. 


\section{Abstract}

During the second half of the $17^{\text {th }}$ Century, coffee houses proliferated in England and, far from being an exceptional phenomenon, they were fully integrated into the daily life of the country. They were public establishments that could be accessed by any man, provided he had the money to afford a cup of coffee. They became places of social interaction far from the private sphere (the home) and the sphere of authority (the court), which achieved recognition thanks to their ideals of sociability, debate and egalitarianism. The coffee houses became the reflection of the daily life of a new emerging middle class, in which empiricism and refinement began to surface. They were linked to the incipient mercantilism of the time, but also had a special impact on English politics and culture. They also received criticism, especially from the female environment, although we must consider them as an opposition to the exclusion that women suffered in order to gain access to certain public spheres. In short, the emergence of coffee houses was the creation of a new space of sociability where it is not a question of excluding any social sector and where opinions began to become public opinion.

Key words: coffee house, sociability, public space, $17^{\text {th }}$ Century, England

El café es un lugar para la cita y la conspiración, para el debate intelectual y para el cotilleo. Abierto a todos; sin embargo, es también una masonería de reconocimiento político o artístico-literario.

George Steiner, La idea de Europa. ${ }^{2}$

\section{INTRODUCCIÓN}

Entendemos la Historia como la ciencia que tiene por objeto el estudio del pasado de una comunidad, asociándola normalmente a una narración de hechos y sucesos que trata de alimentar y modelar un ideario común. De este modo siempre permanecen en la memoria colectiva acontecimientos que interiorizamos y que nos unen como sociedad: el nacimiento de la Monarquía Hispánica, la Revolución Francesa o la caída del Muro de Berlín podrían ser unos ejemplos.

Pero esta manera de entender la Historia nos lleva a olvidarnos de personajes anónimos que han formado parte de la misma o de las pequeñas

2 George Steiner, La idea de Europa. Madrid, Siruela, 2015, p. 38. 
experiencias que jalonan nuestras vidas. Sin embargo nuevas visiones de la Historia, como la historia de lo cotidiano o la historia de género, nos llevan a analizar los hechos históricos desde otras perspectivas. En esta línea se inserta este trabajo, en el que he tratado de estudiar un periodo de ideas convulsas, de expansión comercial y de gran actividad científica, a través de un elemento novedoso y curioso como son las coffee houses. Novedoso por el hecho de ser Inglaterra el primer país europeo donde se asientan este tipo de negocios, ofreciendo un nuevo espacio de sociabilidad entre lo público y lo privado, que servirá para el establecimiento de lo que ciertos autores han denominado opinión pública. Y curioso puesto que, siendo actualmente el té la bebida nacional de Gran Bretaña, sorprende el éxito que las coffee houses y el consumo de café obtuvieron en esta época precapitalista.

Para el desarrollo de este estudio nos hemos basado tanto en obras de autores clásicos, que nos ofrecen una visión estática de las coffee houses como de autores contemporáneos, que desde el siglo pasado relacionan la existencia de estos establecimientos con una nueva práctica de sociabilidad. ${ }^{4}$ En este sentido, destaca una nueva forma de entender el surgimiento de las coffee houses como un indicador del fracaso de las pretensiones monárquicas al absolutismo frente a la creciente influencia de la opinión pública y la participación popular en la política del reino. ${ }^{5}$

Por último quiero precisar el uso de dos términos que intencionadamente no se han traducido: coffee houses y pamphlets. En el primero de los casos he optado por mantener la expresión inglesa coffee houses ya que su interpretación como cafeterías o cafés podría mediatizar la visión que he tratado de ofrecer sobre estos negocios. Mientras que en el caso de pamphlets, su posible traducción por panfletos o folletos presentaría connotaciones peyorativas. Esta lectura inevitablemente nos llevaría a relacionarlos con actividades polémicas o difamatorias, lo que desvirtuaría la importancia que tuvieron este tipo de escritos en la Inglaterra del siglo XVII. En todo caso, su definición más acertada sería la de pequeños libritos en los que se ofrece información o argumentos sobre un tema.

3 Entre estos autores cabe citar a John Evelyn, Thomas Rugge, Robert Hooke o Samuel Pepys.

4 Jürgen Habermas, The structural transformation of the public sphere: an inquiry into a category of bourgeois societ, Cambridge, MIT Press, 1991: 36-37.

5 Brian Cowan, «Publicity and privacy in the history of the British coffeehouse», History Compass 5/4, 2007: 1181-82. 


\section{LA CULTURA DEL CAFÉ}

Poco sabemos sobre la aparición del café como bebida. El origen legendario del café alude a un pastor de la antigua Abisinia que observó el efecto tonificante que la ingesta de unos pequeños frutos había producido en su ganado.

Independientemente de este origen popular, las primeras menciones sobre el café y sus propiedades provienen de médicos persas como Zakariya al-Razi (865-925) o de Ibn Siná, más conocido como Avicena (9801037). Así Al-Razi en su libro Kitab al-Hawi fi al-tibb (El libro integral de medicina, c. 925) comentaba los beneficios positivos de esta infusión. Mientras que Ibn Siná en su tratado Al-qanun fi al-tibb (El canon de la medicina, c. 1020) describía cómo administraba café a sus pacientes como tratamiento de determinadas enfermedades. ${ }^{6}$ Estas referencias indican que el consumo de café era habitual entre los pueblos que vivían en la cuenca del mar Rojo, al tiempo que la rápida expansión del Islam provocó que su consumo estuviera bastante extendido en el mundo musulmán hacia el siglo XV.

Para la mayoría de los musulmanes las cafeterías proporcionaban un lugar de encuentro donde no se entraba en conflicto con las normas coránicas, que impedían vender alcohol, ofreciendo estos establecimientos una atmósfera atrayente y seductora. Estos locales se convirtieron en parte de la sociedad de Oriente Medio, jugando un papel importante en las transacciones comerciales que en ellos se realizaban, pero también generando espacios de entretenimiento y de conversación política.

Los escritores europeos de los siglos XVI y XVII se hicieron eco de estos sentimientos y transmitieron la superioridad de las coffee houses sobre las tabernas, tanto en las bebidas que servían como en las actividades y clientes que atraían. Así, el primer europeo en ofrecernos una descripción del café como «una bebida tan negra como la tinta, útil contra numerosos males» fue el médico y botánico alemán Leonard Rauwolf (1535-1596) en Reise in die Morgenlander (Viaje a las tierras del Este, 1582).?

Centrándonos en el caso inglés, el clérigo William Biddulph en una carta desde Alepo, fechada en 1660, señaló que «Turks' most common

6 Santiago Lascasas Monreal, «Biografía del café», Cuadernos de Aragón 43, 2010: 11-12.

7 William H. Ukers, All about coffee, New York, The tea and coffee trade Journal Company, 1922: 25. 
drinke is Coffa, which is a blacke kinde of drinke, made of a kind of Pulse like Pease, called Coava, which being grownd in the Mill, and boiled in water, they drinke it as hot as they can suffer it». ${ }^{8}$ Otra observación sobre este brebaje la realizó el viajero y poeta George Sandys (1577-1644) al afirmar hacia 1610 que encontraba el café «blacke as soote, and tasting not much unlike it».9

Estas noticias, junto al tráfico comercial que se estableció con Oriente a través de la Levant Company, promovieron un cierto gusto por el café en las clases acomodadas inglesas de principios del siglo XVII. La demanda de café comenzó a aumentar gradualmente en la medida en que los viajeros y comerciantes regresaban del Imperio Otomano adoptando alguna de sus costumbres. De este modo aunque el café fue visto inicialmente como un producto exótico, accesible sólo a una floreciente elite comercial, poco a poco se hizo popular entre las masas llegándose a importar la idea de un establecimiento dedicado a la venta de dicha bebida.

Las cafeterías se fueron estableciendo en las distintas capitales europeas a lo largo del siglo XVII. Oxford fue la primera en 1650 y le siguieron Londres (1652), Viena y Venecia (1683) y finalmente Paris con su famoso Café de Procope (1689)..$^{10}$ Todas ellas proporcionaban un ambiente placentero, que combinaba ocio y negocios en un entorno masculino, y donde la política acostumbraba a centrar los debates. En España, sin embargo, no tenemos noticias de la existencia de cafeterías hasta 1759 cuando la Real Hacienda abrió una Casa de Café para la nobleza, como se reflejó en El Diario noticioso, curioso, erudito y comercial público y económico de 28 de junio de 1759. ${ }^{11}$ Posteriormente se comenzaría a servir café al público en la madrileña Fonda de San Sebastián en 1764. La razón de este retraso en el consumo de café podría explicarse por la exitosa presencia de otra bebida estimulante entre los españoles: el chocolate.

8 «La bebida más común entre los turcos es el coffa, un tipo de bebida negra hecha con una especie de granos parecidos a los guisantes llamados coava, y que, molidos y hervidos en agua, beben tan caliente como soportan». Brian Cowan, The social life of coffee: the emergence of the British coffee house, New Haven, Yale University Press, 2005: 5.

9 «Negro como el hollín y con un sabor no muy diferente de aquél». En Mark Pendergrast, Uncommon grounds: the history of coffee and how it transformed our world, New York, Basic Books, 1999: 8.

10 Markman Ellis, The coffee house a cultural history, London, Weidenfeld and Nicolson, 2004: 259.

11 Pedro Álvarez de Miranda, «Café», Rinconete. Madrid, 2010. 


\subsection{Las coffee houses en la Inglaterra del siglo XVII}

Las primeras coffee houses solían ser establecimientos de una sola habitación, de tamaño variable, situados en la planta baja de los edificios. En ocasiones, el propietario vivía en el mismo edificio y utilizaba una de sus habitaciones para tales menesteres. Normalmente disponían de mesas y bancos corridos, donde tomaban asiento los clientes sin ningún tipo de distinción ni superioridad, llegando a definirse la coffee house como «a place where people of all qualities and conditions meet». ${ }^{12}$ Estaban calentadas por hogares, que también servían para la elaboración de las bebidas, y disponían de una decoración sobria, con pinturas o grabados en las paredes.

Conforme la popularidad de las coffee houses aumentó, se habilitaron espacios reservados, demandados por determinados clientes, a fin de mantener conversaciones privadas. También la decoración evolucionó llegando a exponerse instrumentos científicos, animales exóticos o curiosidades de tierras extranjeras. Pero si por algo despuntaron fue por la oportunidad de leer periódicos, boletines o pamphlets, hasta el punto de que el crítico y lexicógrafo Samuel Johnson (1709-1784) llegó a definirlas como «a house of entertainment where coffee is sold and the guests are supplied with newspapers». ${ }^{13}$ Asimismo se llegó a establecer una coffee house como local de entretenimiento en el propio rio Támesis, cerca de Somerset House: The Folly Coffee House, que tuvo cierto éxito organizando bailes que animaban las noches londinenses.

En este contexto que mezcla comercio, curiosidad y cierto lujo, no es de extrañar que Inglaterra se convirtiese en el primer país europeo donde se instalaron las coffee houses. Así el negocio de las coffee houses, y el mismo consumo de café, surgieron como la adopción de una costumbre exótica por cierta parte de la sociedad inglesa. Una práctica que encontró el respaldo de una burguesía mercantil emergente y que fue idealizada tanto por la literatura de viajes inglesa de principios del siglo XVII, como por las crónicas que aparecen en determinados periódicos de la época.

La primera coffee house de Inglaterra se estableció en Oxford en 1650 gracias a los esfuerzos de un judío libanés llamado Jacob. El éxito llegó

12 «Un lugar donde personas de todas las cualidades y condiciones se encuentran». (Ellis, 2004: 49).

13 «Una casa de entretenimiento donde se vende café y se proporcionan periódicos a los clientes». En Samuel Johnson, A dictionary of the English language, London, J.F. \& C. Rivington, 1785: 407. 
pronto e hizo que se estableciesen negocios de este tipo a lo largo de todo el país, como mostró el topógrafo Thomas Baskerville (1630-1720) en un relato de viajes a través de varios condados, al confirmar la presencia de estos comercios en ciudades como Exeter, Coventry, Newcastle o Bristol. ${ }^{14}$

Pero sin duda alguna la ciudad que reflejó la mayor difusión y crecimiento de las coffee houses fue Londres. La primera coffee house londinense la abrió en 1652 Pasqua Rosee, un empleado de origen griego al servicio de Daniel Edwards, comerciante de la Levant Company. La idea pronto tuvo éxito y, hacia 1708, se estima que en la City y Westminster, los centros del poder político y mercantil inglés, había unas 500 coffee houses, mientras que en todo Londres su número ascendía a 2000.

Estos establecimientos se convirtieron en centros de desarrollo social y económico pues, a diferencia de las tabernas, servían un producto que promovía la lucidez mental y un tipo de pensamiento racional, convirtiéndose al tiempo en un espacio ideal para las transacciones comerciales. A diferencia de las inns, donde su principal negocio consistía en la venta de alcohol y las peleas eran lo habitual, las coffee houses reflejaban control y salud, teniendo a la honestidad, la fiabilidad y la prudencia como principales reclamos. ${ }^{15}$ Determinados autores difundieron estas ideas, entre ellos destacó Thomas Babington Macaulay (1800-1859), que llegó a presentar a las coffee houses como la institución política más importante de Inglaterra, siendo el ejemplo de valores como el igualitarismo o la civilidad. ${ }^{16}$ Virtudes estas que se han insertado en la idea de progreso que llevó a Gran Bretaña de la monarquía absoluta a la libertad.

Algunos autores, influidos por esta corriente de pensamiento whig, afirman como características de las coffee houses la sociabilidad, el debate y el igualitarismo; términos que están siendo reconsiderados por una nueva generación de escritores revisionistas, liderados por Brian Cowan, que tratan de situar los conflictos políticos de la Inglaterra postrevolucionaria en el contexto de una esfera pública emergente. En lo que sí que están de acuerdo ambas corrientes es en la distribución y la atmósfera de tolerancia que ofrecían dichos establecimientos.

14 Steve Pincus, 1688. La primera revolución moderna, Barcelona, Acantilado, 2013: 134.

15 Keith Suter, "The rise and fall of English coffee houses», Contemporary Review 286/1669, 2005: 107.

16 Thomas B. Macaulay, The history of England from the accession of James II, London, Dent \& sons, 1953: 275-278. 
La mayoría de las coffee houses tenían una sala pública donde discutir abierta y libremente, pero también proporcionaban unas pequeñas cabinas donde mantener conversaciones privadas. Este último rasgo se convirtió en habitual en las coffee houses que se situaban cerca del Exchange Alley, muy relacionadas con los negocios financieros del Royal Exchange o Bolsa de Comercio creada en 1571.

Además, las coffee houses invitaban a una conversación lucida y racional debido a la naturaleza de la bebida que se servía; ello se adaptaba a la ética protestante existente y conllevaba debates productivos y negociaciones comerciales exitosas como describía un poeta puritano hacia 1678:

Coffee arrives, that grave and wholesome Liquor, That heals the stomach, makes the genius quicker, Relieves the memory, revives the sad, And cheers the Spirits, without making mad. ${ }^{17}$

Poemas como éste reflejan la aceptación que las coffee houses obtuvieron por toda Inglaterra. No sólo parecía que estos establecimientos promovían la racionalidad y la prudencia, sino que saborear esta bebida era un medio por el cual el consumidor mostraba que valoraba dichas cualidades. Por ello, a diferencia de quienes se dedicaban al trabajo físico, que frecuentaban tabernas para poder desahogar sus penas, la creciente burguesía mercantil del siglo XVII, ocupada en profesiones que implicaban mayor carga de trabajo mental, acudía a las coffee houses buscando un patrón de curiosidad intelectual.

Los diferentes autores están de acuerdo en el aura de civilidad que rodeaba a los debates, ya que con pocas excepciones - la exclusión de las mujeres entre ellas - no existían normas que los regulasen y cualquier persona que pudiera permitirse una taza de café era admitido en ellos. Sin embargo surgió un código de conducta tácitamente aceptado que dispuso las relaciones entre los clientes, delimitando su comportamiento a fin de mantener ciertas pautas de educación: The rules and orders of the coffee house representaron la capacidad de una sociedad para relacionarse sin tener que respetar una jerarquía estricta. Lo único que se esperaba de los

17 «Llega el café, ese licor oscuro y sano, / que cura el estómago, hace el intelecto más rápido, / alivia la memoria, revive la tristeza, / y anima el espíritu, sin volverse loco». En Wolfgang Schivelbusch, Tastes of paradise: a social history of spices, stimulants, and intoxicants, New York, Pantheon, 1992: 34. 
clientes era que pagasen su consumición y que participasen en una conversación intelectualmente sugerente.

En consonancia con la ética puritana dominante, las reglas de este código de conducta surgieron de modo natural sin ser impuestas por ninguna autoridad formal. Esta característica supuso que las facciones políticas realista y parlamentaria, enfrentadas en esa época, aceptasen este código que no suponía una imposición de la otra parte. ${ }^{18}$

El mayor cambio cultural que se produjo a raíz de la consolidación de las coffee houses fue el igualitarismo. Siguiendo la tradición de los cafés turcos, donde se permitía la presencia de cristianos y judíos, cualquiera que entrase en este tipo de establecimiento y pudiese pagar el precio de una taza era considerado como un igual. Las coffee houses revolucionaron la manera en que los hombres conversaban en ellas; de hecho las divisiones económicas, de educación o de nacimiento desaparecieron dentro de unos centros que «estaban abiertos a cualquier hombre, rico o pobre, siempre que pagase su penique y cumpliese las normas». ${ }^{19}$ Medidas de este tipo supusieron un deseo de establecer un nuevo orden favorable a las clases dominantes durante un periodo de gran transformación social, donde una emergente burguesía trataba de ocupar el puesto de la nobleza tradicional.

Frente a la idea de Jürgen Habermas, según la cual las coffee houses eran foros elitistas que legitimaban el dominio de determinados sectores sociales, Pincus afirma que «estos establecimientos se conformaron como una institución democrática que dio lugar al surgimiento de la opinión pública». ${ }^{20}$

\subsection{Beneficios y normas}

Las coffee houses y el consumo de café constituyeron una novedad para la dinámica sociedad inglesa de mediados del siglo XVII. Pero su auge no sólo se vio favorecido por el interés que los comerciantes ingleses sentían por los productos exóticos que traían de ultramar, otros sectores sociales con menos posibilidades económicas también se apuntaron a la moda del café.

18 Aytoun Ellis, The penny universities: a history of the coffee houses, London, Secker and Warburg, 1956: 50.

19 Ralph S. Hattox, Coffee and coffeehouses: the origins of a social beverage in the medieval Near East, Washington, University Press, 1985: 98.

20 Steve Pincus, "Coffee politicians does create: coffeehouses and restoration political culture», The Journal of Modern History 67/4, 1995: 811. 
La principal razón puede residir en el precio de esta bebida, pues como ya hemos expuesto un penique podía considerarse como asumible para la mayor parte de la población.

Además de este tipo de argumentos económicos, es reseñable que en el auge de las coffee houses también encontramos razones publicitarias. Puede ser que el café y las coffee houses fuesen los primeros productos de la era precapitalista que se vieron favorecidos por lo que actualmente denominaríamos una campaña publicitaria.

Edwards y otros comerciantes de la Levant Company ayudaron a Pasqua Rosee en la instalación de su coffee house, pero el animoso mercader griego supo vender su producto apoyándose en un pamphlet donde hacía referencia a las virtudes de esta nueva y exótica bebida. ${ }^{21}$

The vertue of the coffee drink es un pamphlet escrito por Rosee hacia 1652 en el que se detalla el modo correcto de preparar y beber el café y se revelan los beneficios de su consumo. De su lectura observamos cómo en las primeras líneas se asocia el origen del café con su ingesta por grandes señores árabes, con lo que se pretende hacer más atractivo la venta del mismo a los ingleses, colocándolos a la altura de los nobles musulmanes. Después explica brevemente cómo se procede a la elaboración de esta exótica bebida (tostando, moliendo e hirviendo los granos) y propone unos tiempos y temperaturas para obtener todos los beneficios de esta bebida.

Tras estos breves consejos tratando de atraer la atención del público hacia esta nueva infusión, Rosee se dedica a exponer todos los beneficios que su ingesta proporciona. De este modo consideraba que el café evitaba el sueño, podía prevenir abortos, mejoraba la digestión e incluso era un excelente remedio contra enfermedades como los dolores de cabeza, los enfriamientos, la gota, el escorbuto o la tuberculosis. A través del pamphlet, Rosee se revela como verdadero maestro a la hora de vender su producto: por un módico precio el usuario de su coffee house puede sentirse como un sultán persa, al tiempo que disfruta de los saludables beneficios que ofrece la ingesta de café.

Rosee pudo ser el primero en alabar las excelencias del café en beneficio de su negocio, pero no será el único en hacerlo. Hazel Forsyth, historiadora del Gresham College, recoge un anuncio publicado hacia 1657 en The

21 Cowan 2005: 94. 
Intelligencer donde se afirmaba que el café era beneficioso para los ojos, prevenía la somnolencia y facilitaba la realización de negocios. ${ }^{22}$ Realmente, hacia finales del siglo XVII en Inglaterra eran muchos los autores que elogiaban los beneficios de una bebida, el café, que prevenía el raquitismo o los desmayos, contribuía a la producción de orina, evitaba la somnolencia y, en suma, daba vida y regocijaba los espíritus. Así el café se convirtió en una alternativa frente a las bebidas alcohólicas, al tiempo que ofrecía beneficios para la salud de quienes lo consumían.

También en la Monarquía española, a pesar de no tener constancia de locales destinados a la venta de este producto hasta el siglo XVIII, encontramos documentos que lo ensalzan. Así destaca Noticias del caphé, primer libro en castellano sobre el tema escrito en 1692 por el médico palentino Juan de Tariol. En su libro Tariol recoge las experiencias de médicos alemanes, italianos y las suyas propias, contrastando cómo habían utilizado el café para el tratamiento de ciertas enfermedades, así como los éxitos obtenidos. ${ }^{23}$

Si hasta el momento hemos comprobado cómo determinado tipo de publicidad ayudó al establecimiento de las coffee houses, ahora veremos de qué modo el comportamiento que se mantenía dentro de ellas influyó en su reputación.

Una característica definitoria del espacio público es que crea visibilidad. Todo lo que hacemos en este tipo de ámbitos está sujeto a la mirada de los demás y este contexto nos hace cumplir con determinadas normas sociales para proyectar una imagen de corrección hacia los demás.

Como espacios públicos que se desarrollaban en locales privados no cabía una regulación positiva proveniente directamente de la monarquía inglesa. Pero lo cierto es que debido al auge que estaban experimentando las coffee houses, en 1674 se imprimió A brief description of the excellent vertues of that sober and wholesome drink, called coffee, un pamphlet que recogía las excelentes virtudes del café como bebida. En él se incluía un opúsculo titulado The rules and orders of the coffee bouse donde se establecían determinadas reglas de comportamiento que la clientela debía respetar dentro de las coffee houses.

22 Hazel Forsyth, «Seventeenth century», en Lloyd Grossman, ed., London eats out, 500 years of capital dining, London, Philip Wilson, 1999: 46.

23 Socorro C. Calvo Bruzos et al., Manual de alimentación. Planificación alimentaria, Madrid, UNED, 2016: 54. 
En The rules and orders of the coffee house (ofrecemos el texto y su traducción en anexo) se permitía la entrada libre de personas de todo rango social siempre que mantuvieran unas mínimas normas de cortesía. Se evitaba otorgar preeminencia en el acomodo, así como la cesión del asiento, fomentando que el cliente se sentase donde quisiera o donde existiera un hueco libre. Al mismo tiempo se favorecía un debate moderado; para ello, se intentaban evitar fuertes disputas verbales al tiempo que se soslayaban determinados temas de conversación, como el religioso. Y se prohibían ciertos juegos de azar (cartas o dados), así como apuestas superiores a cinco chelines, en un intento de impedir que se generasen disputas que pudieran alterar el ambiente cordial establecido entre la diversa clientela.

Este nuevo modo de reunirse propugnado por las coffee houses ganó popularidad en el Londres de mediados del siglo XVII. Se trataba de una nueva socialización que implicaba una «nivelación social», pues no exaltaba las jerarquías sociales, y ofrecía la bienvenida a todo aquel que pudiese pagar el precio de una taza de café.

Todo ello provocaba una apertura hacia nuevos enfoques a la hora de debatir aspectos políticos y sociales de la época. Personas de diferentes orígenes sociales podían reunirse para discutir sus ideas o para escuchar las experiencias y conocimientos de personalidades que destacaban en otros campos. Toda esta nueva serie de ideas, alimentadas por la cafeína que se suministraba en las coffee houses, sacudieron las mentes de quienes frecuentaban unos locales donde la bebida que se consumía proporcionaba lucidez y sobriedad.

\subsection{Resistencias}

Las opiniones sobre las coffee houses no fueron unánimes, pues mientras unos elogiaban estos locales por sus efectos beneficiosos, otros los consideraron los responsables de determinados males de la sociedad. Los devotos de las coffee houses alababan su sociabilidad, llegando incluso a señalar que eran lugares donde se fomentaba la sobriedad y se mantenía a los hombres alejados del alcohol. Por el contrario, sus detractores las veían como centros de ociosidad, frivolidad y de cultivo de la sedición política; incluso se llegó a asociar a alguno de estos establecimientos con el juego y la prostitución, como fue el caso de Tom King's Coffee House, cuya propietaria Elizabeth Adkins pudo inspirar a Daniel Defoe para su novela, Moll Flanders. Según afirma William Ukers, Defoe era un asiduo visitante de las 
coffee houses, sobre todo de Tom's y Will's Coffee House, una costumbre que seguramente le ayudó a la hora de escribir su célebre novela. ${ }^{24}$

El surgimiento de las coffee houses tuvo sus detractores, siendo varios los grupos que expresaron su oposición a la popularidad y la influencia que adquirían estos negocios. Las primeras críticas vinieron del mundo religioso, pues veían a estos establecimientos como una especie de complot islámico que pretendía envenenar la sociedad cristiana. En este sentido destaca $A$ broadside against coffee, or the marriage of the turk, publicado en 1672. Se quería hacer ver que se estaba copiando una tradición turca, abandonando las tradiciones inglesas, como afirma Nabil Matar: «Tomar café era culturalmente caprichoso y voluble, siendo la inconstancia el primer paso para renunciar al cristianismo». ${ }^{25}$

Otra línea crítica, esta vez desde el mundo económico, venía de los productores de cereal que estaban descontentos, pues el aumento constante de las importaciones de café conllevaba un descenso en la producción y comercialización de las materias primas utilizadas en la elaboración de la cerveza.

Pero las resistencias más importantes y mejor documentadas son las que provinieron desde el colectivo femenino y desde la monarquía. Las mujeres, a través de The maidens complaint against coffee de 1663, The women's petition against coffee de 1674 y The ale wives complaint against the coffee houses de 1675, alertaban de la perdida de masculinidad de sus maridos y del poco tiempo que pasaban en sus hogares. La monarquía, con A proclamation for the suppression of coffeehouses firmada por Carlos II en 1675 , reprochaba a las coffee houses el haberse convertido en lugares donde se incitaba a la sedición.

Aunque las coffee houses se consideraron como un espacio público, esto no quiere decir que fuesen establecimientos abiertos a toda la sociedad, de hecho las mujeres no siempre fueron bien recibidas en aquellas. De aquí que un grupo de mujeres presentara en 1674 una petición para que se procediera al cierre de las coffee houses. En The women's petition se incluía una relación de los grandes daños que producía el consumo excesivo de este secante y debilitante licor, que hacia impotentes a quienes lo bebían, como queda reflejado en las siguientes líneas:

24 Ukers, 1922: 79-80.

25 Nabil Matar, Islam in Britain, 1558-1658, Cambridge, University Press, 1998: 114. 
The men of the coffee house outbabble an equal number of women at gossiping, talking all at once in confusion, and running from point to point insensibly and swiftly. The excessive use of that newfangled, abominable, heathenish liquor called coffee, which riffling nature of her choicest treasures, and drying up the radical moisture, has so eunucht our husbands, and cripple our more kind gallants, that they became as impotent as age, and as unfruitful as the deserts whence that unhappy berry is said to be brought. ${ }^{26}$

The women's petition afirmaba que los cafés eran el refugio de los hombres ebrios hasta que recuperaban cierta sobriedad, al tiempo que les acusaba de perder su deseo sexual por la ingesta de esta infusión. Esta proclama, cuya autoría es discutida, no consiguió su objetivo de cerrar las coffee houses y rápidamente fue rebatida a través de The men's answer to the women petition against coffee (1674). Este nuevo pamphlet reivindicaba las virtudes del café y el comportamiento cortés que los hombres exhibían en estos espacios públicos de sociabilidad. ${ }^{27}$

Bien es verdad que varios comentaristas de la época expresaron su preocupación por las actitudes de ciertos clientes en las coffee houses, muy alejadas de una masculinidad tradicionalmente representada en una taberna alrededor de una cerveza. ${ }^{28}$ En todo este debate los entusiastas del café trataban de contrarrestar las críticas afirmando la capacidad de esta bebida para generar moderación y racionalidad a diferencia del alcohol.

Más autoritaria fue la oposición procedente de la monarquía, aunque tampoco consiguió su objetivo de restringir el acceso a las coffee houses. El 26 de diciembre de 1675 el rey Carlos II firmó A proclamation for the suppression of coffee houses donde se clausuraban este tipo de establecimientos. En esta ley, que debía entrar en vigor el 10 de enero de 1676, se afirmaba que las coffee houses se habían convertido en «the great resort of idle

26 «Los hombres de la coffee house superan a un número igual de mujeres en el cotilleo, hablando todos a la vez en la confusión, y corriendo de un lado a otro insensible y rápidamente. El uso excesivo de ese novedoso, repugnante y pagano licor llamado café, que altera la naturaleza sus más selectos tesoros, y seca la humedad radical, ha castrado a nuestros maridos, y estropeado a nuestros galanes más amables, convirtiéndolos en impotentes por edad, y tan infructuosos como los desiertos de donde se dice que se trae esa infeliz baya». Anónimo, The women's petition against coffee representing to publick consideration the grand inconveniencies accruing to their sex from the excessive use of that drying, enfeebling liquor: presented to the right honorable the keepers of the liberty of Venus. London, 1674.

27 Ukers, 1922: 71.

28 Pincus, 1995: 823. 
and disaffected persons to them». ${ }^{29} \mathrm{El}$ resultado fue el contrario al pretendido, los disturbios se extendieron por el reino y Su Majestad tuvo que derogar el decreto unos días antes de su entrada en vigor. Ellis pone de manifiesto que esta proclama era «un esfuerzo por subvertir el sistema parlamentario» ${ }^{30}$ ya que Carlos II había prorrogado la convocatoria del Parlamento y gobernaba sin él pretendiendo de este modo eliminar todo atisbo de oposición política. Aunque en estas condiciones los decretos del rey sólo podían modificar ligeramente las leyes del reino, esta actitud fue vista como un intento de reintroducir el autoritarismo real, llegando a hablarse de una conspiración de los Estuardo para quebrantar el poder del Parlamento.

La oposición a las coffee houses no sólo vino de la monarquía, también grupos como los realistas acusaron a la clientela de estos establecimientos de difundir informaciones falsas y de generar conspiraciones. Se llegó a afirmar que estos locales se habían convertido en seminarios para la sedición y en oficinas para el envío de mentiras. ${ }^{31}$ Una idea que como veremos tomaría todavía más fuerza a la luz de las revoluciones americana y francesa del siglo XVIII y que afirmaría la naturaleza subversiva de las coffee houses.

Lo cierto es que la retirada del decreto fue vista como una conquista por parte de una emergente opinión pública, pero también puede considerarse como una pequeña victoria del monarca pues se introdujo una nueva variable: la vigilancia. Tras la anulación de $A$ proclamation for the suppression of coffee houses el gobierno trató de utilizar estos establecimientos como un instrumento para recopilar información e intentar reprimir ciertas actividades conspiradoras. Este intento por controlar la opinión pública pudo influir en la posterior caída de las coffee houses al cercenarse la libertad de expresión en los debates que se celebraban en ellas.

Estas actitudes de resistencia hacia las coffee houses ponen de manifiesto la preocupación existente por la conducta y los nuevos modos de interacción social que se desarrollaban en aquellas. Ni la oposición de las mujeres ni la del monarca tuvieron nada que ver con el café, su consumo y venta. En el primer caso parece que la disputa pudiera tener su origen en el

29 «El gran punto de reunión de personas ociosas y desafectas a la monarquía». Charles II, King of England, By the King: a proclamation for the suppression of coffee houses. London, 1675.

30 Ellis, 1965: 90.

31 Pincus, 1995: 829. 
tiempo que los hombres pasaban en estos locales, algunos de ellos asociados a la prostitución, abandonando sus deberes conyugales. Mientras que en el caso de la respuesta ofrecida por el soberano y su gobierno las causas podían centrarse en motivos políticos, no podemos olvidar que Carlos II hacía poco tiempo que había recuperado el trono de su padre y las actitudes políticas desarrolladas en las coffee houses podían poner en peligro su autoridad.

\section{COFFEE HOUSES Y SOCIEDAD}

El establecimiento de las coffee houses a finales de los años 1650 y 1660 constituyó una especie de revolución social. Su rápido auge y el éxito alcanzado por alguna de ellas transformaron el mundo de la economía, la política y la cultura. Muchas de estas coffee houses se convirtieron en centros de negocios y de debate, pero otras se vieron involucradas en intrigas y maquinaciones llevando al gobierno de Carlos II a plantear su cierre.

Las coffee houses se convirtieron en nuevos espacios de sociabilidad donde gentes de diferentes condiciones sociales participaban en debates y conversaciones. Esta apertura intelectual ayudó a idear nuevos negocios, a plantear los descubrimientos científicos de un modo menos académico o a criticar determinadas creaciones literarias. En definitiva, lo que se pudo observar fue la inclusión de nuevas ideas que favorecieron el crecimiento intelectual de la sociedad inglesa.

A lo largo de los siguientes apartados trataremos de ver la influencia que las coffee houses tuvieron en diversos aspectos de la sociedad de la época. Unos centros que, ayudados por el ambiente que reinaba en ellos, facilitaron debates, posibilitaron la transferencia de ideas y ayudaron a la creación de redes clientelares que potenciaron no sólo el mundo económico, sino también el científico y el cultural.

\subsection{Economía}

Quizás las entidades más relevantes asociadas a la cultura del café fueron las instituciones financieras. Durante los siglos XVII y XVIII Londres se convirtió en un centro de comercio internacional de primer nivel y sus coffee houses tuvieron una influencia significativa en el desarrollo de teorías e instituciones financieras. Las coffee houses resultaron ser lugares públicos pero con relativa privacidad, donde compradores y vendedores podían reunirse, negociar transacciones y fijar los precios de mercado. 
De este modo, las coffee houses se convierten en lugares para hacer negocios, atendiendo a los orígenes mercantiles de sus creadores. The Jamaica Coffee House fue un lugar de reunión donde los comerciantes de las Indias Occidentales cerraban tratos; a The Jonathan's Coffee House asistían trabajadores de la Moscovy Trading Company fundada en 1555; e incluso en The Garraway's Coffee House se llegaron a publicar los precios de las acciones de determinadas compañías. ${ }^{32}$

La principal virtud que las coffee houses ofrecían a este nuevo sistema económico fue el buen ambiente que reinaba en ellas. La sobriedad y el buen juicio que se presumía a su clientela proporcionaban inmejorables condiciones para las prácticas comerciales y la negociación. Comerciantes y corredores se unían en un ambiente sociable para tratar de realizar negocios basados en la mutua confianza, la respetabilidad y la honestidad.

Todo ello evidenciaba que comerciantes y hombres de negocios necesitaban disponer de noticias actualizadas para la buena marcha de sus intereses, pero también de lugares donde dicha información se pudiese consultar y debatir. Así pues, las coffee houses se convirtieron en centros de circulación de noticias, donde podían consultarse boletines que incluían precios de productos o noticias políticas y comerciales.

Esta necesidad de información llevó al boticario John Houghton (1645-1705) a imprimir un boletín donde se pretendía mejorar la agricultura y el comercio. De este modo publicó un repertorio, que se distribuyó a través de las coffee houses, donde establecía un catálogo completo de los diversos tipos de tierras, los productos más adecuados para su cultivo, el mejor tipo de estiércol para cada uno de ellos, o el arte de drenaje y riego de tierras.

Uno de los más preclaros hombres de negocios que surgieron de este nuevo mundo económico en desarrollo fue Edward Lloyd (1648-1713), que fundó su coffee house hacia 1688 y consiguió hacerse con información fiable sobre navegación y embarques. Su establecimiento se había convertido en un lugar donde comerciantes, marineros y armadores se reunían para cerrar sus transacciones, lo que fue aprovechado por Edward para desarrollar su negocio. ${ }^{33}$

32 Heather Lynn McQueen, "London coffee houses: the first hundred years», Honors theses, Richmond, University Press, 2004: 23.

33 Pendergrast, 1999: 13. 
Edward Lloyd no entró en el negocio del seguro sino que se limitó a recoger información y ponerla a disposición de sus clientes. Colocó un estrado donde les ofrecía información relativa a embarques y subastas relacionadas con las transacciones marítimas. Esta actuación marcó el inicio de una evolución que hizo que Lloyd's dejase de ser una coffee house para convertirse en una prestigiosa compañía de seguros.

Tras la muerte de su propietario y después de más de 80 años como establecimiento dedicado a la venta de café, una serie de clientes tomaron la decisión de crear la compañía de seguros. Este nuevo Lloyd's comenzó a cobrar una cuota de suscripción a sus asociados, al tiempo que les proporcionaba información de primera mano, para finalmente en 1774 dedicarse únicamente a realizar negocios como la aseguradora que conocemos hoy en día.

Algo parecido sucedió con la Jonathan's Coffee House en el Exchage Alley, donde sus socios podían negociar en la planta baja y tomar cafés en las habitaciones de la planta superior. Este tipo de negocios también pasó a los Estados Unidos donde la Tontine Coffee House comenzó realizando funciones aseguradoras, para posteriormente hacia 1817 convertirse en el germen de la actual Bolsa de Nueva York.

Toda esta transformación evidenció la disminución de la importancia del negocio del café, pero permitió la creación de una serie de actividades especializadas que caracterizarán la escena financiera londinense desde el siglo XVII hasta nuestros días.

Incluso las coffee houses participaron en el incipiente y desorganizado servicio postal. En 1643 Carlos I legalizó el uso de los correos reales para el transporte de correspondencia privada, pero estos correos no demostraron ser un método de comunicación muy satisfactorio para el público en general. Durante los mandatos autoritarios de los primeros Estuardo y el periodo republicano, la privacidad no era la característica dominante en el servicio postal, lo que posibilitaba la apertura de la correspondencia y el conocimiento de su contenido por parte del Gobierno. Por esta razón surgió un tipo de correo privado que trataba de garantizar la privacidad en las entregas: William Dockwra hacia 1680 organizó el Penny Post para repartir entregas en Londres y Westminster por el precio de un penique. Este negocio garantizaba la entrega de la correspondencia a sus destinatarios, y utilizaba las coffee houses como puntos de recogida a la manera de los actuales apartados de correo. La idea se extendió y el gobierno autorizó la apertura de nuevos negocios en diferentes ciudades de Inglaterra, Escocia e Irlanda, 
convirtiéndose en el embrión del actual Royal Mail. ${ }^{34}$ El crecimiento de Londres debido a la emigración rural — se estima que pasó de una población de 200000 habitantes en 1603 a unos 575000 en $1695^{35}$-, hacía más fácil y eficiente enviar correo a las coffee houses que tratar de localizar y dirigir cartas a la vivienda de una persona. Esta nueva funcionalidad provocó que la gente frecuentase habitualmente estos negocios en busca de las noticias de sus familiares o sus localidades natales, al tiempo que facilitó el contacto con otras personas que se encontraban en las mismas circunstancias.

\subsection{Política}

Una de las diferencias entre las tabernas y las coffee houses se encuentra en el modo en que se interactuaba en ellas. Mientras la taberna estaba pensada como un lugar donde encontrar compañía y aprobación, la coffee house se centraba en el estímulo y el debate. En ambas se hablaba de temas de administración y gobierno pero mientras en las tabernas se alababan las actuaciones de los diferentes líderes, las coffee houses se convertían en foros de debate y crítica política.

Este ambiente de libertad de pensamiento fue aprovechado por los dos partidos políticos que habían surgido en estos momentos: los whig y los torys. La división política conllevó que ciertas coffee houses se identificasen con cada una de estas dos corrientes políticas e incluso tras la Revolución de 1688 los disidentes jacobitas lograron mantener vivos sus ideales en determinados establecimientos cafeteros, como Ozinda's Chocolate House.

El partido whig, que venía a aglutinar las clases burguesas surgidas tras la decapitación de Carlos I, se dio cuenta del potencial que tenían estos establecimientos a la hora de divulgar sus ideas. Así, en la época de la Crisis de la Exclusión (1679) ${ }^{36}$ Fair's Coffee House, Rainbow's Coffee House, Garraway's Coffee House - donde se leían las arengas del conde de Shaftsbury o el duque de Buckingham contra Carlos II-, o Jonathan's Coffee House representaban el más genuino sentir de esta corriente política. Los torys no se quedaron atrás y también tenían locales proclives a sus ideas. Entre ellos destacaron Will's Coffee House o Sam's Coffee House.

34 Thomas Todd, William Dockwra and the rest of the undertakers: the story of the London Penny Post, Edinburg, C.J. Cousland and Sons, 2010: 49.

35 McQueen, 2004: 19.

36 La Crisis de la Exclusión fue motivada por un proyecto de ley fallido que trataba de excluir de la línea sucesoria al futuro Jacobo II por su declarado catolicismo. 
A pesar de las divisiones políticas, apoyadas por las numerosas coffee houses, es notable observar lo conscientes que fueron los propietarios de estos negocios en cuanto a los discursos que se producían en ellos, pues permitieron que los oradores informasen de las tertulias que se realizaban en otros establecimientos. Lejos de crear un mundo fragmentado, formado por camarillas excluyentes, el espacio surgido alrededor de las coffee houses durante la Restauración se convirtió en un sistema donde las diferentes partes se comunicaban entre sí.

No sólo se produjeron enfrentamientos dialecticos entre los diferentes partidos que comenzaban a organizarse en la Inglaterra del siglo XVII. También las coffee houses fueron utilizadas por el poder político real para informar del cariz que tomaban los diferentes conflictos bélicos en los que se veía envuelta la monarquía inglesa. De este modo se dispersaron rumores del maltrato que sufrían los marineros ingleses durante la guerra angloholandesa de 1665, posiblemente con la finalidad de obtener el apoyo de la ciudadanía a tal enfrentamiento.

Pero el ejemplo más paradigmático que se puede encontrar de este clima de libertad política, de libertad de expresión y de enfrentamiento de ideas es el levantamiento de las colonias norteamericanas frente a su metrópoli. Aquí The Green Dragon Coffee House jugó un papel fundamental en su inicio, pues se convirtió en el primer cuartel general de los revolucionarios al acoger las reuniones secretas de los Sons of Liberty (Hijos de la Libertad) y ser la sede el 16 de diciembre de 1773 del Boston Tea Party, desencadenante de la Guerra de Independencia.

\subsection{Cultura}

Aun cuando la importancia de las coffee houses llegó a deteriorarse, estos centros mantuvieron su jerarquía como foros de discusión vibrante sobre aspectos literarios y científicos. Muchos de los personajes ingleses más influyentes de los siglos XVII y XVIII se reunieron en locales de este tipo propiciando el intercambio de ideas. Figuras como Dryden, Swift, Pope, Pepys o Hooke se reunieron en coffee houses para debatir sobre temas literarios y científicos, imbuidos por el espíritu empirista de Francis Bacon. Los postulados que defendían, afirmando que la verdad no nace de la autoridad y que el conocimiento deriva sobre todo de la experiencia, les llevaron a trasladar sus conocimientos a unos espacios públicos donde podían ser sometidos a crítica.

En cuanto a la literatura, el Will's Coffee House en la londinense Russell Street, presidido por la figura del poeta y dramaturgo John Dryden (1631- 
1700) atrajo a los literatos más famosos y talentosos de Inglaterra. Dryden supo mantener su fidelidad primero a Cromwell y más tarde a Carlos II, lo que le valió para ser nombrado por este último como Poeta Laureado. ${ }^{37}$ Años más tarde el Bedford's Coffee House, en la zona de Covent Garden, recogería el testigo del análisis literario convirtiéndose en el termómetro que evaluaba los estrenos teatrales. Escritores consagrados y aspirantes se reunían para conversar, unos expresando sus opiniones y otros esperando hacerse un nombre. Tras la muerte de Dryden, Will's Coffee House experimentó un descenso en su popularidad, lo que fue aprovechado por sus competidores: el Tom's Coffee House, visitado por el poeta romántico Thomas Chatterton, y el Button's Coffee House, base de operaciones de los periodistas Joseph Addison y Richard Steele. Todos estos cafés literarios fueron conocidos por adoptar un punto de vista particular sobre la poesía y el teatro del momento, siendo el germen de lo que actualmente conocemos como crítica literaria. En este sentido, destaca el Button's Coffee House, fundado en 1712 cerca de Covent Garden, donde Addison, Steele, Pope o Swift se reunían para debatir sobre las nuevas obras de teatro, poemas o novelas levantando y destruyendo reputaciones literarias.

Las coffee houses también jugaron un importante papel en la difusión de las gacetas o pamphlets, sobre todo gracias a la oferta que en ellas se hacía de periódicos como The Tatler (1709-1711) o The Spectator (1711-1712), impulsados por Joseph Addison y Richard Steele. Vinculados al pensamiento whig — de hecho Addison fue parlamentario-, trataron de acercar la filosofía a la sociedad. Sus escritos, con intención satírica y moralizadora, intentaban ofrecer herramientas para que sus lectores pudieran mantener conversaciones adecuadas en establecimientos como las coffee houses donde la clientela presentaba un alto grado de heterogeneidad. Del mismo modo, estos autores son los responsables de la idea de igualitarismo asociada a las coffee houses, pues en muchos de sus escritos trataron de ofrecer una visión amable de estos locales, evitando connotaciones negativas.

Por otra parte, las coffee houses también revolucionaron la comunidad científica inglesa del siglo XVII, algunos autores de la época llegaron a considerar que las polémicas surgidas en este tipo de negocios mejoraron el conocimiento tanto como las universidades. ${ }^{38}$ Gracias a estos locales, los

37 Poeta laureado era el título que recibía aquel escritor nombrado por el Gobierno para la glosa de los grandes acontecimientos de estado.

38 Walter H.G. Armytage, "Coffee houses and science», Nova et Vetera (British Medical Journal) 16, 1960: 213. 
debates científicos perdieron gran parte de su naturaleza abstracta y elitista, haciéndose más prácticos y concentrándose en debatir problemas de la vida cotidiana. Markman Ellis haciendo un paralelismo con la sociedad actual compara el papel de las coffee houses con el de Internet al permitir el acceso de personas comunes a nuevos tipos de conocimiento. ${ }^{39}$

Como ejemplos de estos intentos de acercar la ciencia al público destacaron Peter Staelh, que enseñó química en Tillyard's Coffee House; sir William Petty (médico y economista) que estableció una tertulia en Turk's Head Coffee House; o John Harris, que dio conferencias sobre matemáticas en Marine's Coffee House. Incluso hay que destacar la creación de varias sociedades científicas como la Botanical Society, fundada en 1721 y que se reunía en Rainbow's Coffee House, y la Royal Society of Arts, surgida de las reuniones mantenidas hacia 1754 en Rawthmell's Coffee House. ${ }^{40}$

Pero, sin lugar a dudas, el mejor ejemplo de esta apertura científica lo representa la Royal Society of London for Improving Natural Knowledge, más conocida como la Royal Society. A lo largo de la década de 1640 un grupo elitista de médicos y filósofos comenzó a reunirse regularmente en el Gresham College de Londres. Durante el periodo de inestabilidad de las guerras civiles un pequeño grupo de ellos, no conformes con el modo en que se desarrollaban las sesiones, se separó comenzando a reunirse en el Tillyard's Coffee House. Durante el gobierno de Cromwell adoptaron el nombre de Oxford Coffee Club y poco a poco fueron ganando en notoriedad hasta que en 1662 obtuvieron el patronazgo del rey Carlos II y constituyeron la Royal Society. ${ }^{41}$

La Royal Society obtuvo rápidamente el permiso de Carlos II, parece ser que en su afán de eliminar la notoriedad que había adquirido The Rota, un coffee club fundado por James Harrington con la finalidad de difundir los ideales republicanos que había plasmado en su obra Oceana. ${ }^{42}$ Las reuniones de la Royal Society carecían del ambiente típico de jerarquía y austeridad que reinaba en el Gresham College. Esta fue una de las razones de su éxito, ya que hicieron accesible la ciencia a un amplio público de dife-

39 M. Ellis, 2004: 158.

40 Edward F. Robinson, The early history of coffee houses in England: with some account of the first use of coffee and a bibliography of the subject, New York, Cambridge University Press, 2013: 79.

41 Robinson, 2013: 80.

42 Ukers, 1922: 60. 
rente condición social y creencias. Estos «científicos de coffee house» participaron de un diálogo con el público que acudía a estos establecimientos enriqueciendo el conocimiento científico. Pero este mismo carácter abierto sirvió para que recibieran duras críticas por parte de los científicos más tradicionales, pues estos consideraban que dichas reuniones tenían una naturaleza superficial y poco estructurada al permitir la participación de individuos poco instruidos.

\section{UN ESPACIO PÚBLICO}

La primera coffee house londinense se abrió en pleno distrito financiero y no fue por casualidad. Fue patrocinada, en cierto modo, por comerciantes de la Levant Company que se habían acostumbrado a beber café durante sus estancias en ciudades como Estambul, Esmirna o Alepo. Estos establecimientos, que comenzaron a proliferar durante el periodo republicano inglés, encontraron un público preparado gracias al clima político de discusión que se había generado durante los años precedentes. Por lo cual podemos afirmar que estas coffee houses estaban asociadas desde sus inicios a una cierta clase de interacción social o sociabilidad, caracterizada por el igualitarismo y la conversación.

Estos negocios se fueron convirtiendo en puntos de reunión y sociabilización de gran parte de la población inglesa. El mencionado John Houghton llegó a afirmar que las cafeterías vuelven sociables a toda clase de personas, desarrollan las artes, el comercio y todas las demás áreas del conocimiento humano. ${ }^{43}$ Las descripciones contemporáneas de las cafeterías enfatizaron su carácter inclusivo: eran lugares donde extranjeros y nativos, visitantes y lugareños intercambiaban noticias y rumores sobre el mundo exterior. Así se desprende de la definición que sobre las coffee houses ofrece Henry Misson de Valberg:

These houses, which are very numerous in London, are extreamly convenient. You have all manner of news there: you have a good fire, which you may sit by as long as you please: you have a dish of coffee; you meet your friends for the transaction of business, and all for a penny, if you don't care to spend more. ${ }^{44}$

43 John Houghton, «A discourse of coffee». Philosophical Transactions 21, 1699: 312.

44 «Estas casas, que son muy numerosas en Londres, son extremadamente convenientes. Allí tienes toda la noticia: tienes un buen fuego, junto al cual puedes sentarte todo el tiempo que quieras: tienes un plato de café; te encuentras con tus amigos para la 
Así vemos que más allá del consumo de café, las actividades centrales de las coffee houses eran la conversación y la discusión. Para que estas ocupaciones se pudiesen canalizar se instauró una especie de regulación implícita, las coffee houses establecieron un conjunto de dinámicas de grupo que les permitió crear una sociabilidad distinta: una conversación participativa y en tono agradable, lo que las diferenciaba del ruidoso ambiente de las tabernas.

Para Habermas, la vida social de las coffee houses representa las importantes transformaciones que sufrió la sociedad inglesa durante el siglo XVII. De este modo los espacios públicos innovadores, como las coffee houses, permitieron la construcción de lo que él define como 'esfera pública burguesa'. Estos establecimientos promovieron un tipo de discusión desinhibida, tranquila y pausada, facilitando una interacción que ignoraba temporalmente las distinciones de rango, ${ }^{45}$ fomentaban la tolerancia y eran accesibles a un gran número de personas.

Cowan matiza la declaración de Habermas al afirmar que «the coffee house was a public house much like the alehouses, inns, and taverns that had long formed a part of the British urban landscape». ${ }^{46}$ De este modo considera que las coffee houses, entendidas como lugar de reunión, no supusieron una innovación.

Steve Pincus incide en esta idea de espacio público, pero propone que el factor que distingue a las coffee houses de cualquier otro foro público es el interés de los propietarios por el éxito del negocio y no por halagar a determinados clientes elitistas excluyendo a otros. ${ }^{47}$ Este igualitarismo estableció la idea de que todos los clientes tenían el derecho a participar en las discusiones que se generaban y que todas las opiniones eran igualmente respetables. Fue el inicio de una nueva noción de esfera pública donde se permitía compartir y debatir opiniones, y donde los hombres consideraban que su participación era un deber cívico.

Para definir estos espacios, Oldenburg acuñó el término «tercer lugar», que ofrece una vía de escape a la relación que se produce entre el hogar y

transacción de negocios, y todo por un céntimo, si no te importa gastar más». En Henry Misson de Valberg, Memoirs and observations in his travels over England. With some account of Scotland and Ireland, London, D. Browne, 1719: 39-40.

45 Habermas, 2005: 36.

46 «La coffee house era una casa pública como las cervecerías, las posadas y las tabernas que habían formado parte del paisaje urbano británico». Cowan, 1991: 79.

47 Pincus, 1995: 814-815. 
el lugar de trabajo. Este tercer lugar se define por instaurarse en un terreno neutral, lo que permite la nivelación social, con la conversación como elemento que une a unos clientes que vuelven con asiduidad. La accesibilidad y la asiduidad son las características que proporcionan a estos terceros lugares un ambiente agradable, donde la gente se encuentra relajada y puede interactuar con sus iguales. ${ }^{48}$

Según estas ideas podemos establecer determinadas características de esta esfera pública:

- La esfera pública es un rasgo distintivo de la sociedad moderna en el sentido de que la autoridad pública comienza a cambiar, refiriéndose menos a la vida cortesana y más a las actividades que se desarrollan en un sistema estatal (no feudal) emergente. Con el estado moderno las economías, que en el sistema feudal solían ser privadas, pasan a ser públicas y a orientarse hacia un mercado amplio de consumidores.

- La esfera pública tiene lugar en privado, o en ciertas regiones limítrofes entre lo público y lo privado, siendo las coffee houses el ejemplo por excelencia. Suele generarse en un espacio privado, pero ofrece la singularidad de que el acceso a los mismos en principio no está limitado. Así observamos que la línea entre lo público y lo privado no siempre está totalmente definida. Lo público podrá desarrollarse en la esfera privada (coffee houses en locales o habitaciones de casas particulares), pero también veremos intercambios privados en espacios de la esfera pública (coffee houses como lugares donde se realizan transacciones privadas).

- En estos nuevos ámbitos, representados por las coffee houses, la gente participa en la discusión racional y crítica que se establece. Esto obliga a formular juicios razonados que fundamenten las opiniones, evitando las brusquedades tan frecuentes en otros establecimientos. Aunque no siempre será así el respeto del turno de palabra, la actitud receptiva hacia las opiniones de los otros y la no ingesta de alcohol favorecerán la creación de un ambiente ideal para estas nuevas zonas de interacción social. Básicamente la sociabilidad de los seres humanos busca lugares donde se sientan bienvenidos y conectados.

48 Ray Oldenburg, The great good place, New York, Paragon House, 1989, p. 34. 
- Finalmente, la esfera pública nace como un territorio al que puede acceder cualquier persona, su existencia se produce por la simple accesibilidad de los individuos y la coffee house permite esta aproximación. Se observa que no se limita la entrada a la clientela, que la consumición es relativamente barata y que no se obliga a un consumo continuo. En este sentido los espacios públicos son áreas que las personas pueden ocupar, pero esta idea no debe llevar a afirmar que estos espacios están abiertos a todos pues siempre habrá grupos excluidos. En el caso de las coffee houses fueron las mujeres quienes quedaron marginadas y empujadas hacia la invisibilidad.

\section{Conclusiones}

En este ensayo se ha tratado de elaborar una síntesis sobre la situación en que se produce el surgimiento de las coffee houses en la Inglaterra del siglo XVII, así como sobre las consecuencias que su aparición conllevó en aspectos tan relevantes de la sociedad inglesa como los negocios, la cultura o la política.

El origen de las coffee houses se encuentra, sin duda, en el flujo mercantil existente entre Inglaterra y el Cercano Oriente. Gracias a ese trasvase de mercancías no sólo se importaron bienes, sino que también se adoptaron costumbres arraigadas en las sociedades orientales. Los comerciantes ingleses se vieron gratamente sorprendidos por espacios donde se podía mantener tranquilamente una conversación alrededor de una bebida caliente; por ello, a su vuelta al desapacible clima inglés trataron de recrear aquellos ambientes.

A este propósito ayudaron tanto la bebida como las circunstancias que rodearon la apertura y posterior auge de las coffee houses. En cuanto a la bebida, la aparición y el consumo del café observamos dos premisas: la novedad y el precio de la misma y los beneficios que reportaba para la salud. El bajo precio que se abonaba por tomar una taza de café sirvió para que estos locales tuviesen una buena acogida por la clientela inglesa; además, la posibilidad de prolongar la estancia en estos establecimientos sin sentirse obligados a consumir continuamente y la perspectiva de obtener una compañía agradable y lúcida compensaba el carácter amargo de la nueva bebida.

De otro lado, la publicidad que se realizó enumerando las múltiples virtudes del café no hizo sino reforzar la sincera acogida y el crecimiento de este tipo de negocios donde el debate, la lectura y la buena compañía 
ejercían de reclamo para la clientela. Periodistas como Addison y Steele trataron de elogiar el ambiente de las coffee houses como lugares de reunión de una nueva elite comercial y social que quería alejarse del entorno más degradado que representaban las tabernas. Pero no debemos caer en el error de pensar que el ambiente en este tipo de negocios siempre fue placentero: algunas ilustraciones nos ofrecen imágenes de discusiones exaltadas y de compañías poco recomendables. En todo caso, sin llegar a considerar las coffee houses como el espacio de armonía que trasmiten las crónicas periodísticas de la época, sí se puede afirmar que estos locales supusieron un gran cambio en las conductas de quienes acudían a ellos.

Además, la adopción por parte de los propietarios de unas mínimas normas de convivencia a respetar dentro de las coffee houses favoreció la consolidación de este tipo de negocios basados en el respeto y la «nivelación social». Las coffee houses se convirtieron en locales donde las diferencias sociales quedaban diluidas en beneficio de un ambiente agradable y una conversación lúcida.

Pero no todo en el desarrollo de las coffee houses fueron elogios y dichas y también tuvieron que sufrir las resistencias y la oposición de diferentes sectores sociales. Aunque la Iglesia en principio las desaprobó al considerar las coffee houses como un intento de islamización, la favorable acogida que recibieron por gran parte de la sociedad inglesa hizo inútil su resistencia.

Algo similar ocurrió con las prohibiciones que la Corona inglesa trató de imponer a este tipo de negocios. Carlos II quiso ver a las coffee houses como centros de intriga política contra la recientemente reinstaurada monarquía de los Estuardo. Pero tanto la oposición de los propietarios como la de los clientes, así como la pérdida de beneficios que conllevaría el cierre de estos establecimientos para su gobierno, le obligaron a retirar su legislación restrictiva.

Más importantes, pero igualmente ineficaces, resultaron las críticas formuladas hacia las coffee houses procedentes del colectivo femenino. Determinados autores han planteado que tras estas críticas se escondían eclesiásticos, pero la esencia de las mismas elimina el elemento religioso, como queda reflejado en The maiden's complaint, The women petition $\mathrm{y}$ The ale-wives complaint. Posiblemente el motivo principal de esta recriminación pueda encontrarse en la ingratitud que las mujeres sufrieron por parte de sus maridos, pero es más plausible que el origen de la resistencia femenina hacia las coffee houses fuera el rechazo a un espacio donde la visibilidad social de la mujer era nula. Creemos que su queja tiene más que 
ver con tratar de ocupar un determinado espacio público de nueva creación, que con desavenencias conyugales.

Estas reticencias conducen a reflexionar sobre una de las características que muchos autores han otorgado a las coffee houses: el igualitarismo. Siempre contextualizando históricamente este concepto, estos establecimientos se caracterizaban por la igualdad entre quienes los frecuentaban, pero ello no quiere decir que todos pudieran acceder a ellos en completa igualdad. Sería iluso pensar que las mujeres en la Inglaterra del siglo XVII ejercían de los mismos derechos que los hombres, cuando todavía no han alcanzado este estatus de igualdad en la mayor parte de nuestras sociedades contemporáneas.

Esta misma reflexión puede hacerse referida a personas que practicaban una religión distinta a la mayoritaria, como el caso de los católicos. El fenómeno de las coffee houses se desarrolla tras una guerra civil en la que el elemento religioso ha sido determinante, incluso existe una corriente política que propugna la imposibilidad de que los monarcas ingleses practiquen el catolicismo. En 1689, el Acta de Tolerancia tratará de cerrar estas heridas, pero siempre en el contexto de tolerar las diferentes confesiones reformadas, excluyendo a los católicos. Esta situación induce a pensar que los católicos difícilmente se encontrarían cómodos en unos establecimientos donde se debatió, se comerció o se experimentó según los nuevos modos que el mercantilismo y el empirismo comenzaban a imponer.

En cuanto a la influencia que las coffee houses ejercieron en la sociedad inglesa no tenemos nada más que observar algunos ejemplos que todavía resisten el paso del tiempo: la Royal Society, la compañía de seguros Lloyd o la existencia de clubs donde los socios mantienen animados debates políticos o literarios son claros ejemplos del peso de estos establecimientos.

En términos económicos, las coffee houses favorecieron la creación de espacios públicos donde compartir información mercantil y ello provocó la aparición de nuevos tipos de negocios que favorecieron la expansión de la economía inglesa. La existencia de las coffee houses, caracterizadas por la transferencia de noticias e ideas, ayudó a la creación de nuevas figuras jurídicas relacionadas con el tráfico de bienes. Asimismo, el mayor nivel de alfabetización y la posibilidad de consultar boletines y hojas de noticias donde se incluía información mercantil o agrícola facilitaron el crecimiento de una sociedad que tenía en el comercio su principal fuente de ingresos.

No sólo el mundo económico y financiero se benefició de las coffee houses. Multitud de pamphlets y periódicos se distribuyeron a través de 
estos locales; en ellos se criticaba a autores literarios e incluso se valoraban las actuaciones de los actores en los estenos teatrales. Toda esta actividad sirvió para generar un nuevo tipo de opinión pública que podía ensalzar o denigrar a cualquier figura de la sociedad inglesa.

En el plano político también se advirtieron las posibilidades que ofrecían las coffee houses para tratar de captar adeptos o de modelar la ideología de la clientela, lo que constituyó uno de los principales motivos de la prohibición establecida en 1675 por Carlos II. Este potencial político queda patente en el protagonismo alcanzado por estos establecimientos como centros de reunión durante el periodo revolucionario norteamericano.

Finalmente, los científicos también supieron aprovechar las oportunidades que les ofrecieron las coffee houses. Muchos de ellos, vetados o imposibilitados para acudir a las universidades, se sirvieron de estos espacios públicos para exponer sus teorías o realizar sus experimentos. Existen pamphlets que documentan la celebración de ensayos en varias coffee houses, pero quizás el ejemplo más definitivo de la vinculación de estos negocios con el mundo de la cultura fue la creación en uno de ellos de la Royal Society.

Todo lo expuesto nos lleva a concluir que la aparición de las coffee houses en Inglaterra permitió el nacimiento de un nuevo espacio público, donde la jerarquía social se dejó de lado en beneficio de la creación de un ambiente que favorecía el trasvase de ideas. Personajes como Milton, Bacon, Harvey, Newton, Pope, Swift, Wren o Boyle frecuentaron las coffee houses, Aunque sus trabajos no se hubiesen visto mermados por no acudir a ellas, sin duda su obra no hubiese tenido tanta trascendencia como la que alcanzó en su momento ni hubiera podido llegar a un número tan elevado de individuos.

A partir del análisis de las fuentes primarias que incluimos en anexo, nuestro estudio permite constatar la influencia que ejercieron las coffee houses inglesas en la creación de unos nuevos espacios públicos donde la sociabilidad, la igualdad y la comunicación fueron características principales, y donde las opiniones particulares comenzaron a convertirse en opinión pública.

\section{REFERENCIAS}

\section{Fuentes}

Anónimo, The women's petition against coffee representing to publick consideration the grand inconveniencies accruing to their sex from the excessive use of 
that drying, enfeebling liquor: presented to the right honorable the keepers of the liberty of Venus, London, 1674.

Anónimo, The ale-wives complaint against the coffee-houses: in a dialogue between a victuallers wife and a coffee-man, being at difference about spoiling each others trade: with several articles at last concluded upon between them for the setling what customers, London, printed for John Tomson, 1675.

Anónimo, A brief description of the excellent vertues of that sober and wholesome drink, called coffee, and its incomparable effects in preventing or curing most diseases incident to bumane bodies, London, Printed for Paul Greenwood, 1674.

Charles II, King of England. By the King: a proclamation for the suppression of coffee houses., London, printed by the Assigns of John Bill and Christopher Barker, printers to the Kings most Excellent Majesty, 1675.

\section{Referencias bibliográficas}

Álvarez de Miranda, Pedro, 2010, «Café», Rinconete, Madrid.

ARmytage, Walter H. G., 1960, «Coffee houses and science», Nova et Vetera (British Medical Journal) 16: 213.

Calvo Bruzos, Socorro Coral, Carmen Gómez Candela, Consuelo López Nomdedeu y Bricia López Plaza, 2016, Manual de alimentación. Planificación alimentaria. Madrid, UNED.

Cowan, Brian, 2007, «Publicity and privacy in the history of the British coffeehouse», History Compass 5/4 (2007): 1180-1213.

Cowan, Brian, 2005, The social life of coffee: the emergence of the British coffee houses. New Haven, Yale University Press.

DeKKer, Rudolf y Lotte VAN DE POL, 2006, La doncella que quiso ser marinero. Madrid, Siglo XXI.

Duby, George, 2010, Guillermo el Mariscal. Madrid, Alianza.

ElLIS, Aytoun, 1965, The penny universities: a history of the coffee houses. London, Secker and Warburg.

ELLIS, Markman, 2004, The coffee house a cultural history. London, Weidenfeld and Nicolson.

EvelYN, John, 1906, The diary of John Evelyn. New York, Macmillan.

Forsyth, Hazel, 1999, «Seventeenth Century». En Lloyd Grossman, ed., London eats out, 500 years of capital dining. London, Philip Wilson: 31-47.

Ginzburg, Carlo, 2012, El queso y los gusanos. Barcelona, Península.

HABERMAS, Jürgen, 1991, The structural transformation of the public sphere: an inquiry into a category of bourgeois society. Cambridge, MIT Press.

HATTOX, Ralph S., 1985, Coffee and coffee houses: the origins of a social beverage in the Medieval Near East. Washington, University Press. 
Hooke, Robert, 1968, The diary of Robert Hooke M.A., M.D., F.R.S. 1672-1680, London, Wykeham Publications.

Houghton, John, 1699, «A discourse of coffee», Philosophical Transactions 21: 311-317.

Johnson, Samuel, 1785, A dictionary of the English language. London, J.F. \& C. Rivington.

Lascasas Monreal, Santiago, 2010, «Biografía del café», Cuadernos de Aragón, 43 (2010): 9-78.

Macaulay, Thomas Babington, 1953, The history of England from the accession of James II. London, Dent and sons.

MatAR, Nabil, 1998, Islam in Britain, 1558-1658. Cambridge, University Press.

MCQUEEN, Heather Lynn, 2004, «London coffee houses: the first hundred years», Honors theses, Richmond, University Press.

Misson de VAlBerg, Henry, 1719, Memoirs and observations in his travels over England. With some account of Scotland and Ireland. London, D. Browne.

Muralt, Louis de, 1725, Lettres sur les anglois et les françois et sur les voiages.

Oldenburg, Ray, 1989, The great good place. New York, Paragon House.

PENDERgRast, Mark, 1999, Uncommon grounds: the history of coffee and how it transformed our world. New York, Basic Books.

PEPYs, Samuel, 1904, The diary of Samuel Pepys, London, G. Bell.

PINCUS, Steve, 2013, 1688. La primera revolución moderna. Barcelona, Acantilado.

PINCUS, Steve, 1995, «Coffee politicians does create: coffeehouses and restoration political culture», The Journal of Modern History 67/4 (1995): 807-834.

ROBINSON, Edward Forbes, 2013, The early history of coffee houses in England: with some account of the first use of coffee and a bibliography of the subject. New York, Cambridge University Press.

Rugge, Thomas, 1961, Mercurius Politicus Redivivus. London, Royal Historical Society.

SCHIVELBUSCH, Wolfgang, 1992, Tastes of paradise: a social history of spices, stimulants and intoxicants. New York, Pantheon.

STEINER, George, 2015, La idea de Europa. Madrid, Siruela.

SUTER, Keith, 2005, «The rise and fall of English coffee houses», Contemporary Review, 286/1669 (2005): 107-110.

TODD, Thomas, 2010, William Dockwra and the rest of the undertakers: the story of the London Penny Post. Edinburg, C.J. Cousland and Sons.

Ukers, William Harrison, 1922, All about coffee, New York, The tea and coffee trade Journal Company.

VAN HoRn MELTON, James, 2001, The rise of the public in Enlightenment Europe, Cambridge, University Press. 


\section{Anexos}

1. The Vertue of the Coffee Drink (c. 1652). Transcripción y traducción.

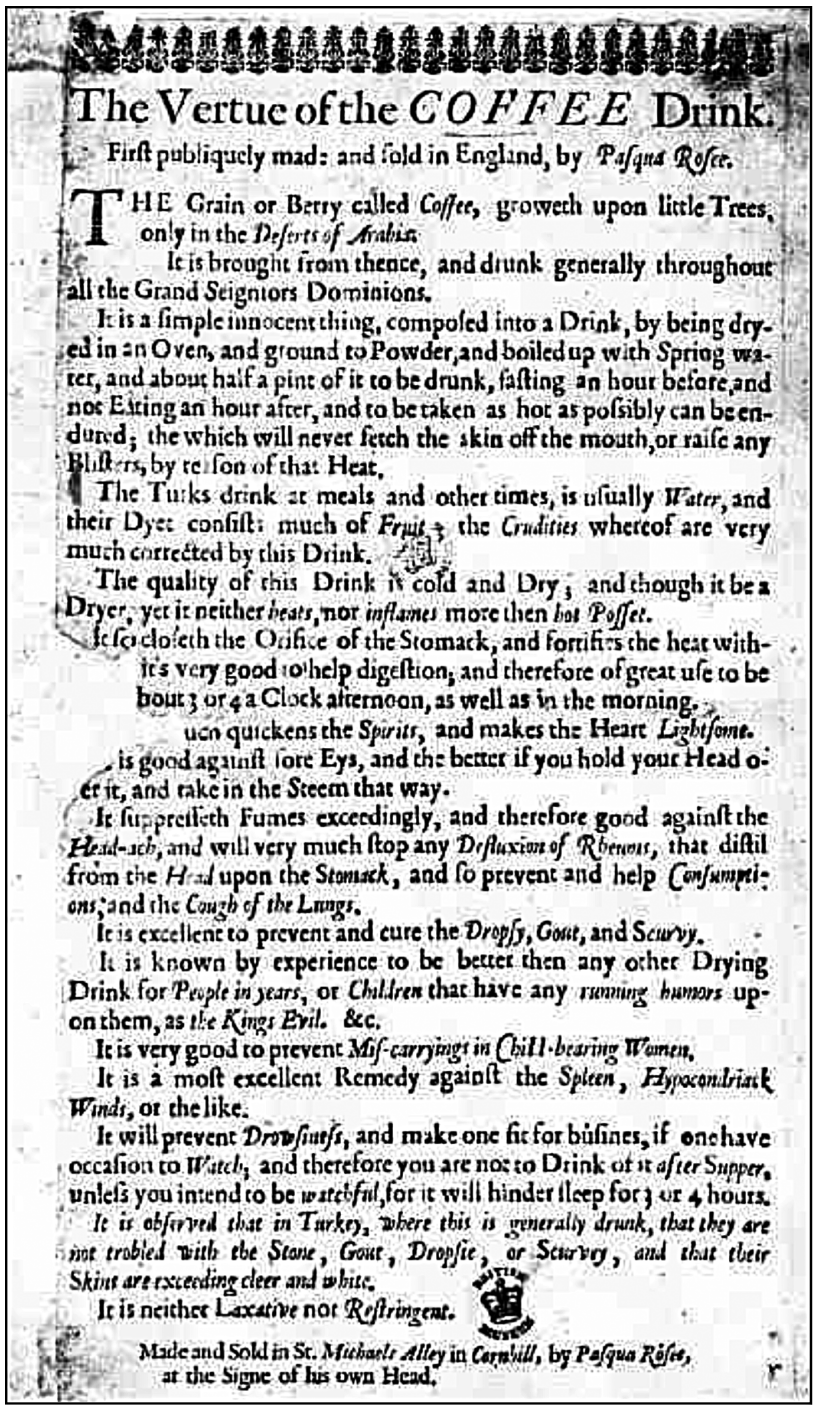

1. 'The vertue of the coffee drink'. Pamphlet escrito por Pasqua Rosee, c. 1652. 


\section{THE VERTUE OF THE COFFEE DRINK}

First publiquely mad: and sold in England, by Pascua Rosee

THE Grain or Berry called Coffee, groweth upon little Trees, only in the Deserts of Arabia.

It is brought from thence, and drunk generally throughout all the Grand Seigniors Dominions.

It is a simple innocent thing, composed into a drink, by being dryed in an Oven, and ground to Powder, and boiled up with Spring water, and about half a pint of it to be drunk, fasting an hour before and not Eating an hour after, and to be taken as hot as possibly can be endured; the which will never fetch the skin off the mouth, or raise any Blisters, by reason of that Heat.

The Turks drink at meals and other times, is usually Water, and their Dyet consists much of Fruit, the Crudities whereof are very much corrected by this Drink.

The quality of this Drink is cold and Dry; and though it be a Dryer, yet it neither heats, nor inflames more than hot Posset.

It forcloseth the Orifice of the Stomack, and fortifies the heat with [lac.] its very good to help digestion, and therefore of great use to be [lac.] bout 3 or 4 a Clock afternoon, as well as in the morning.

[lac.] quickens the Spirits, and makes the Heart Lightsome.

[lac.] is good against sore Eys, and the better if you hold your Head o'er it, and take in the Steem that way.

It supresseth Fumes exceedingly, and therefore good against the Head-ach, and will very much stop any Defluxion of Rheumas, that distil from the Head upon the Stomach, and so prevent and help Consumptionsand the Cough of the Lungs.

It is excellent to prevent and cure the Dropsy, Gout, and Scurvy.

It is known by experience to be better then any other Drying Drink for People in years, or Children that have any running humors upon them, as the Kings Evil. \&c.

It is very good to prevent Miscarryings in Child-bearing Women.

It is a most excellent Remedy against the Spleen, Hypocondriack Winds, or the like.

It will prevent Drowsiness, and make one fit for Busines, if one have occasion to Watch, and therefore you are not to drink of it after Supper, unless you intend to be watchful, for it will hinder sleep for 3 or 4 hours.

It is observed that in Turkey, where this is generally drunk, that they are not troubled with the Stone, Gout, Dropsie, or Scurvy, and that their Skins are exceeding cleer and white.

It is neither Laxative nor Restringent.

Made and Sold in St. Michaels Alley in Cornhill, by Pasqua Rosee, at the sign of his own head translate. 


\section{LA VIRTUD DE LA BEBIDA DE CAFÉ}

\section{Primero publicado y vendido en Inglaterra por Pascua Rosee}

El grano o baya llamado café crece en pequeños árboles sólo en los desiertos de Arabia.

Se trae desde allí y se bebe a lo largo de los dominios de los grandes señores.

Es una cosa sencillamente inocente, convertida en bebida mediante secado en un horno, y molida en polvo y hervida con agua de manantial, bebiéndose una media pinta [unos $250 \mathrm{ml}$, ayunando una hora antes y no comiendo una hora después, y debe ser tomada tan caliente como se pueda aguantar, de tal modo que nunca resecará la piel de la boca, ni levantará ampollas a causa de ese calor.

Los turcos lo beben en las comidas y demás ocasiones, como si fuese agua, y como su dieta se basa en frutas, la acidez de las mismas es corregida por esta bebida.

La naturaleza de esta bebida es fría y seca, y aunque sea seca ni calienta ni enardece más que un posset caliente. ${ }^{1}$

Cierra el orificio del estómago, y fortifica el calor con [lac.] es muy buena para ayudar a la digestión, y por lo tanto de gran utilidad para ser $[\text { lac. }]^{2}$ hacia las 3 o las 4 de la tarde, así como por la mañana.

[lac.] estimula los espíritus y alegra el corazón.

[lac. $]^{3}$ es bueno contra los ojos inflamados y lo mejor si mantienes la cabeza sobre él, y tomas el tallo de este modo.

Elimina vapores, y por lo tanto es bueno contra el dolor de cabeza, y deten- drá cualquier formación de flemas, que fluyen de la cabeza hacia el estómago, y así previene y ayuda contra la tos.

Es excelente para prevenir y curar la hidropesía, la gota y el escorbuto.

Se sabe por experiencia que es mejor que cualquier otra bebida para gente mayor, o para niños que tienen humores como el mal del rey, etc.

Es bueno para prevenir los abortos en parturientas.

Es un remedio excelente contra los males del bazo o los aires hipocondriacos.

Evita la somnolencia y te pone en forma para los negocios si uno tiene ocasión de observarlo, y por lo tanto no se debe beber después de cenar, a menos que se tenga la intención de permanecer alerta, porque dificulta el sueño durante 3 o 4 horas.

Se observa que en Turquía, donde se duele beber, no tienen problemas con piedras, gota, hidropesía o escorbuto, y que su piel está limpia y pálida.

No es laxante ni restringente.

Hecho y vendido en el callejón St. Michel, en Cornhill, por Pascua Rosee...

1 El posset era una bebida de leche cuajada mezclada con algún licor.

2 Se propone: tomada, ingerida.

3 Se propone: hervida, inhalada. 
2. Rules and Orders of the Coffee House (1674). Transcripción y traducción.

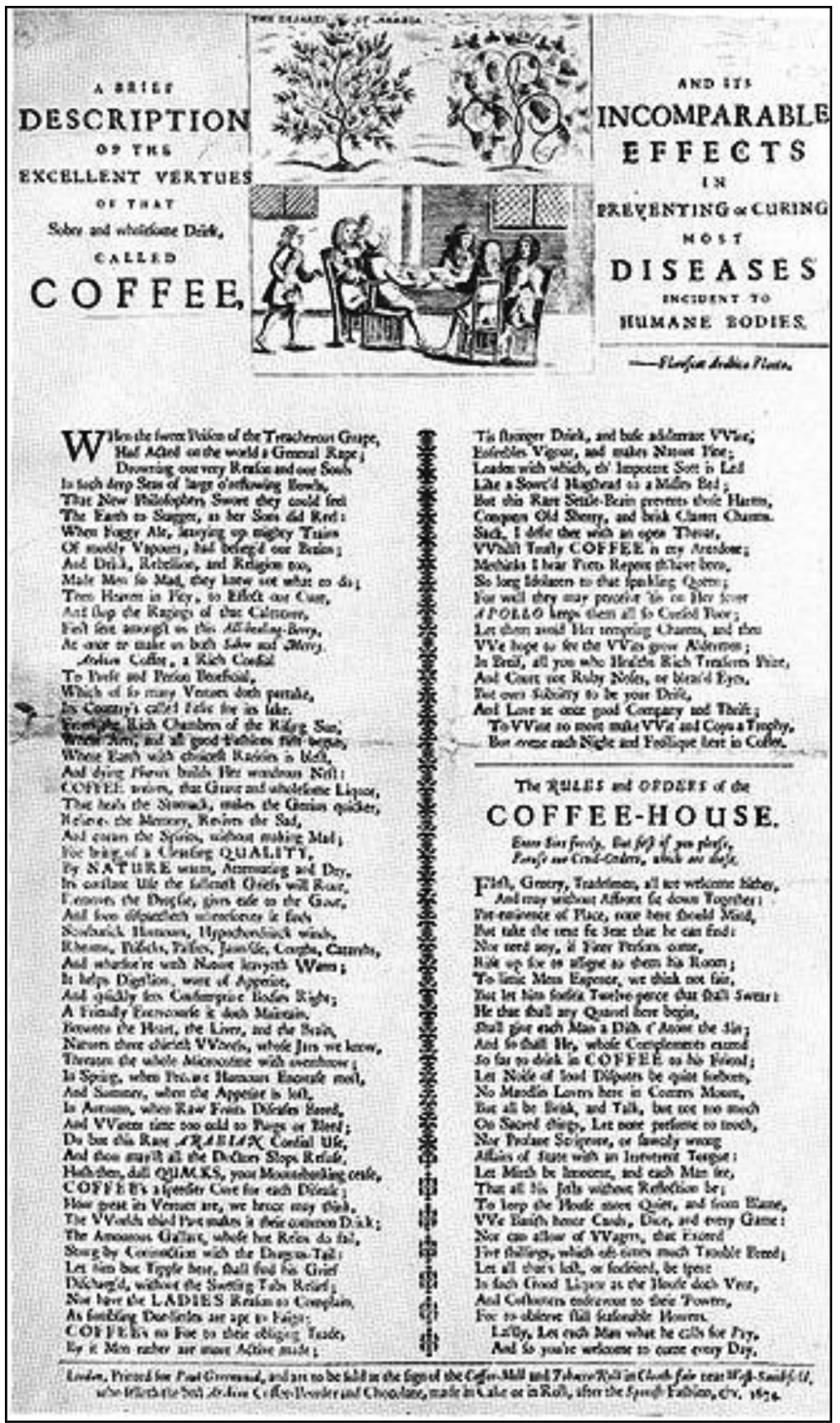

2. 'Rules and Orders of the Coffee-House', en un pamphlet de 1674. 


\section{THE RULES AND ORDERS \\ OF THE COFFEE-HOUSE}

Enter, sirs, freely, but first, if you please, Peruse our civil orders, which are these.

First, gentry, tradesmen, all are welcome hither,

And may without affront sit down together:

Pre-eminence of place none here should mind,

But take the next fit seat that he can find:

Nor need any, if finer persons come,

Rise up for to assign to them his room.

To limit men's expense, we think not fair,

But let him forfeit twelve-pence that shall swear:

He that shall any quarrel here begin,

Shall give each man a dish t' atone the sin;

And so shall he, whose compliments extend

So far to drink in coffee to his friend;

Let noise of loud disputes be quite forborne,

Nor maudlin lovers here in corners mourn,

But all be brisk, and talk, but not too much;

On sacred things, let none presume to touch,

Nor profane Scripture, nor saucily wrong

Affairs of State with an irreverent tongue:

Let mirth be innocent, and each man see That all his jests without reflection be;

To keep the house more quiet and from blame,

We banish hence cards, dice, and every game;

\section{REGLAS Y ÓRDENES \\ DE LA COFFEE-HOUSE}

Entren, señores, libremente pero, primero, si lo desean

Lean atentamente nuestras normas de cortesía, que son éstas:

En primer lugar, gentry, comerciantes, todos son bienvenidos, Y pueden sin ofender sentarse juntos; Ninguna preeminencia de lugar debe importar,

Solamente que tome el siguiente asiento que pueda encontrar,

No hay necesidad, si vienen personas más elevadas,

De levantarse para ceder el acomodo.

Para limitar el gasto de los hombres, creemos que no es justo,

Deja que pierda 12 peniques que maldecirá:

Y ni iniciará ninguna pelea aquí,

Daremos a cada hombre una taza para expiar el pecado

Y así será, extendiendo sus respetos

Hasta tomar café con sus amigos;

Deja que el ruido de fuertes disputas sea acallado

Ni los amantes se aflijan en los rincones

Pero sé enérgico y habla, pero no demasiado;

Sobre cosas sagradas, que ninguno se tome la libertad de hablar

Ni profane las Escrituras, ni hable mal

Sobre asuntos de Estado con lenguaje irreverente;

Deja que la alegría sea inocente y que cada hombre vea

Que sus bromas son sin crítica;

Para mantener la casa tranquila y sin culpa 
Nor can allow of wagers, that exceed. Prohibimos las cartas, los dados

Five shillings, which ofttimes do troubles breed;

Let all that's lost or forfeited be spent

In such good liquor as the house cloth vent,

And customers endeavour, to their powers, y cualquier juego

Ni podemos permitir apuestas que excedan

De 5 chelines, que muchas veces engendran problemas;

Deja que todo lo que se pierda se gaste

For to observe still, seasonable hours. Lastly, let each man what he calls for pay, And so you're welcome to come every day.

En un buen licor...

Y los esfuerzos de los clientes, a su potestad

Para respetar los oportunas horas.

Finalmente deja que cada hombre pague lo que pida,

Y así serás bienvenido para venir cada día. 
